\title{
The Twenty-Third Triennial Conference Games: Playing with competition at an academic conference
}

\author{
John Lean
}

Manchester Metropolitan University

j.lean@mmu.ac.uk

\section{ARTICLE INFO}

Article history:

Received 29 October 2019

Accepted 26 March 2021

Keywords:

Play

Games

Competition

Adult learning

\begin{abstract}
At the 2019 Playful Learning conference, I designed and ran a crossconference game that was focused on the idea of competition in education and play. Whilst play and competition are connected in literature, this relationship is not necessarily seen as a positive one, and my game provided a space to interrogate the relationship between the two. Discussion of the conference game, via reflection on its design and conversation with the players, opens up into more general discussion of competition's role in play (and play in education). I find that, in this specific context, competition facilitated and provoked playfulness in unexpected ways.
\end{abstract}

\section{Introduction: Making Friends}

Contestant 1: I'm not here to make friends.

Contestant 2: I ain't gonna make one friend.

Contestant 3: I'm just here to win. I'm not here to make friends!

Host: Okay. No. You're here to make friends. 'Making Friends' is the name of this show.

[Title Card: 'Making Friends']

(Comedy Central, 2014, 0:02)

In the fake reality TV show in this Kroll Show sketch, the contestants are incapable of not competing with each other. They have bought so completely into the logic of game shows that their default position is to compete, even when the host tells them explicitly not to. The humour here stems from the idea that people really do see competition in this way; we all know someone who frames everything in competitive terms, and who would

Published under Creative Commons License 4.0

First publications rights: (C) University of Huddersfield Press unipress.hud.ac.uk

Volume 2, Issue 1. 
jump at the chance of taking part in one of these reality shows.

In the field of play studies, competition is a provocative topic because of the way in which it interacts with other forms of play, and because of the way in which competitive players interact with non-competitive ones. Beyond this, competition (especially economic competition) seems to pervade other aspects of our lives. For example, in the education system, schools and universities compete with each other, whilst individual students are ranked and rated in what seems to be a competitive system. As both an educationalist and a play scholar, I am interested in the tension around competition, and in this article, I explore how this tension might be a productive site for playfulness.

First, I interrogate the literature to examine the roots of potential friction between competition and other aspects of play. I then take these ideas 'into the field' by examining a specific example of competition: my design for the 'conference game' at the 2019 Playful Learning conference. Through designing this game and examining how it ran in practice, I identify two specific ways in which the relationship between competition and play might be complicated. Firstly, it is compatible with more collaborative forms of play; and secondly it can provide a site for subversion and creative rule-breaking behaviours. Both of these might mean that competition is more about 'making friends' than it might seem.

\section{Theoretical background: Play and competition}

There is a complicated relationship between play and competition that goes back to the foundational texts of games and play scholarship. For Huizinga (1949), play and competition are inextricably linked because they both draw upon the uncertainty of tension and release, with sporting competition exemplifying the height of this tension. Caillois (1961) goes into more depth on this idea, positioning competition (or agôn) as one of four categories of play and games; the others being chance (alea), simulation (mimicry) and chaos or vertigo (ilinx). These categories imply certain approaches to play and games; for example, agôn is dependent on alea (as Huizinga also suggests) but incompatible with ilinx, which introduces too much chaos and destroys the conditions under which competition can take place. Juul (2005, p. 10) points out that both Huizinga and Caillois cover broad categories that encompass both play and games, which is exacerbated by the 'language issue' of some languages not distinguishing between these terms (or at least distinguishing between them in different ways). The upshot of this is that they often refer specifically to games as illustrations of wider points about play, which may explain why their arguments focus on competitive sport. This is a similar theme for Suits (1978), whose discussion of play as defined by goals frequently draws upon running races as goal-driven competition. In all three of these cases, there is a sense that play and competition link simply because of the examples that the authors choose to illustrate their points, and because of the dominant types of (competitive, masculine) games 
that were prominent when they wrote. This is reflected by Sutton-Smith (1997), whose idea of 'rhetorics of play' highlights that any discourse around play will depend on the types of games and players discussed, and the purpose of the approach itself. This also comes across in other theories of play. Hutt argues that play becomes more competitive and rule-bound as players age out of childhood (1981, p. 272), which might explain why a focus on adult play can often mean an emphasis on competition.

More recent approaches to games and play question the necessity of competition assumed by others, often because they work towards different purposes and discuss different games. De Koven (2013) argues that competition is something that needs to be transcended as players learn to 'play together' to keep the game going (a process he calls 'coliberation'). For De Koven, there is a distinction between 'having to win' and 'playing to win', with the former focused more on straightforward competition, and the latter on playing the game for the sake of play. Salen and Zimmerman (2003, pp. 256-7) draw attention to the fact that De Koven's work needs to be understood as part of the New Games Movement which tried to use large-scale games to transform society and mediate conflict, and which therefore had an ambivalent relationship towards competition. Yet again, Sutton-Smith's rhetorics are relevant here. This approach speaks to more recent critical approaches, which react to the foundational texts of play studies in light of new play forms. Flanagan (2009) and Sicart (2014) both highlight the potential of games and play to undermine and critique existing rule structures, but do not find a place for competition in their conceptions of play.

Play can be understood as an escape from reality, and part of the motivation for critical theorists' disdain for competition in play might be because competition is so prevalent elsewhere in the world. Writing in the mid20th century, Caillois (1961) suggested that a focus on competition had caused a decline in other forms of play and culture, and later Kohn (1992) argued that competition is uncritically understood as an inevitable outcome of human nature in all aspects of life. Now, competition still seems to be the dominant mode of interaction under neoliberalism, and is actively encouraged by political, economic and social structures (Brown, 2015; Davies, 2014). In my own field of higher education, for example, competition exists between and within institutions as they become increasingly subject to marketisation (Connell, 2019).

Given this, it is unsurprising that critical approaches have the disregard that they have towards competition. Building upon Caillois' argument, Bateman (2018) critiques gamification because it overemphasises competition in play (and real-life) to the detriment of the freedom and chaos that play can provide. Even in ostensibly competitive settings, too much competition is seen as a dangerous thing. In their ethnographic exploration of a pick-up softball team, Kolb and Kolb highlight the 'tenuous balance between competition and fun' that players had to maintain (2010, p. 39). Some players were more competitive than others were, and play effectively became a site for negotiation around what constituted too much competition. This links to the idea of playstyles, 
which acknowledges that different players might have different motivations to play. For example, Bartle (1996) frames videogame players into four distinct categories, some of whom are more competitive than others. Brown (2009) at a more fundamental level, describes individuals 'play personalities' that incline them towards particular play experiences in the first place, and he includes 'the competitor' as one of these. According to these approaches, competition is not a necessary condition of play, but rather something that particular players bring with them and are drawn to, and that others try to avoid. Importantly, this effectively forms an ecosystem as those players who prefer competition depend to some extent on those who do not in order to have something to compete against (de Albuquerque \& Fialho, 2015), although again there is a fine balance between competition and fun to be negotiated.

There is a connection between the idea of playstyles and rhetorics of play. In both cases, players or theorists have a particular preference for competition that stems from their understanding of what competition actually does. For some, it is central to the play experience, for others it is peripheral. Further, for some it is to be actively discouraged as it gets in the way of what play is meant to be about. Whether thinking theoretically or practically, the role of competition in play is complicated because of this, and this speaks to the key takeaway from the literature that there is an ambivalence towards competition. It seems at odds (or even incompatible) with more cooperative approaches to play, especially those that are intended to empower players. Given the context I outline below, this tension between competition and cooperation will be central to the rest of my argument.

\section{Contextual background: The Playful Learning conference}

Since 2016, the Playful Learning conference has located itself at the intersection of play and adult learning, and provided 'a space where teachers, researchers and students can play, learn and think together' (Playful Learning Conference, 2019, online). Across keynotes, workshops and activities, attendees spend three days exploring the role that play and games can have in settings like universities, libraries and professional training, often by sharing and experiencing playful activities that presenters have devised in their own educational work. As part of this process, the organising committee commission a 'conference game' (Piatt, 2019) that includes everyone who attends the conference. This is intended to break the ice between delegates, especially newcomers to the conference, and then provide a structure for 'off-timetable' moments; if delegates need something to do, the game is there to entertain, inspire or guide them. The game also often has a 'theme' that unifies the rest of the conference; in 2017 it was soft toys, and in 2018 it was pirates. These slightly silly themes are representative of a much wider atmosphere at Playful Learning that makes it clear it is not an 'ordinary' conference.

Having recently completed a PhD exploring play in higher education, I was tasked with designing and running the conference game for Playful Learning 2019, which took place at the University of Leicester in early July. My 
own research into play in adulthood had begun to explore some of the ideas around competition outlined above, in particular the relationship between competition as it exists in play contexts, and competition as it is understood in universities as neoliberal institutions. In addition, my $\mathrm{PhD}$ thesis argues that play offers undergraduates and academics a chance to change their relationship to participation, and that this can be encouraged through the use of games and play not as learning tools but as frames for wider experiences that can change students' understanding (Lean, 2019). In this way, I align myself more with the critical studies of play mentioned above, especially as I see myself as having a personal preference for non-competitive play. The conference game was a chance to put some of these ideas and preferences into practice.

Given all of this, I had three aims for the conference game:

- Design and run a game that would provide a playful space for conference delegates to interact.

- Run an 'experiment' in competition, exploring some of the tensions between play and competition.

- Push myself out of my comfort zone as a game designer by giving myself a design concept that I would normally avoid, that seemed at odds with the collaborative games I have used in the classroom.

For the remainder of this paper, I want to explore how my approach to these aims actually worked, drawing upon some of the literature I have already outlined.

\section{The design: The Twenty-Third Triennial Conference Games}

\section{The gameplan}

The Twenty-Third Triennial Conference Games, as my game became known, was roughly based on the idea of the Olympics as an archetypal competition. At the simplest level, delegates were tasked with earning gold, silver and bronze medals by taking part in challenges across the conference, and these medals contributed points to both individual and team leader boards over the course of the conference.

On paper, delegates could earn medals in three main ways: they could be given them by session leads, who had tokens to hand out for their own tasks; they could take part in conference-wide challenges and games that ran centrally; or they could challenge each other independently before reporting to one of the conference 'referees' (including me) who would adjudicate and award medals accordingly.

We awarded medals in the form of gold, silver and bronze plastic tokens, but delegates were encouraged to exchange these for corresponding stickers as often as they could. This meant that they could drop their tokens into a team 'totaliser' that acted as a physical leader board, and in return receive stickers that they could attach to their conference lanyards, thus 'wearing' their medals around their necks. This also enabled me to register any medals earned on my labyrinthine medal spreadsheet.

This was the basic structure of the game, but at a higher level I also designed a plotline that would guide 
players through the conference, and link to some of the more critical points outlined above. In summary, my aim was to recreate many of the activities that happen around competitive sport, without necessarily having an actual sport in the middle. I spent the budget for the game on sports paraphernalia, including refereeing equipment (whistles, stopwatches, tape measures) and the sorts of sports equipment that might be required for a primary school sports day (bean bags, quoits, sponge footballs and cones), but there was no requirement for any of these to be used in a particular way. Instead, I tried to create a space in which players might use all of these things to explore the idea of competition around three themes that I chose to encourage them to 'break' the game in critical ways.

\section{Ceremony}

On the first day of the conference, the key theme of the game was 'ceremony'. In order to embed the idea of competition, I drew upon obvious symbols of competition that even the least sports-aware participants would recognise. Even the way I titled the game the Twenty-Third Triennial Conference Games, and the fictional history I built around it, was intended to justify all of the imagined traditions that we enacted.

The first of these traditions started prior to the conference. Delegates were assigned to a team (Blue, Purple or Yellow) via email, with each of the conference chairs acting as team captain. Delegates were encouraged to dress in their team colours for the duration of the conference, and most delegates did so to some extent. Some wore a yellow tie or a blue headband; others wore every item of purple clothing in their wardrobe and painted their faces to match.

In this introductory email, I also asked delegates to share photographs of the Conference Games torch wherever they were, with the idea that this would create a virtual torch relay of all the places from which delegates were travelling. Of course, points were available for the team that posted the most pictures across the greatest distance. In the week before the conference, I regularly tweeted out a Google Map of all of the places in the world that delegates had photographed the torch, with pins colour-coded by team, and this began to build a sense of competition among some delegates.

This fed into an 'opening ceremony' that took place at the start of the first day. I created an animation of the torch being lit, and made delegates stand for the official anthem of the Games. After explaining the rules, delegates also uttered an oath based on the Olympic oath, and, collectively, came up with a team chant that they could use to cheer each other on. In the evening, we put on board games and competitions in order to provide as many opportunities as possible for delegates to earn medals.

These early activities also effectively provided a tutorial for the game itself. Upon registering, delegates automatically earned a medal and went through the process of registering it and adding it to their team's total, 
so they could see how the process worked. There was an element of ceremony to this. I encouraged referees to treat the process with solemnity as if they were truly acting as arbiters of a major decision.

By the end of the first day, the goal was that players understood the process of earning and registering medals, and that we had established a pattern that could then be subverted on the following days.

\section{Bureaucracy}

On day two of the conference, my aim was to begin to undermine the 'positive' vision of competition from the previous day by introducing some of the more negative aspects of sport (I labelled this 'bureaucracy' in my plan). Doing so involved interfering with the teams' efforts and trying to frustrate (deliberately) their efforts to earn medals.

Early in the day, I began to inflate artificially the individual score of one of the conference chairs. Every time the medal table shifted, I made sure that she was always at least ten points out in front. This meant that by the start of the second keynote just before lunch I was in a position to make an official announcement that she had been caught cheating (all of this was faked, but done with her permission). I left the true nature of these accusations vague and allowed delegates to draw their own conclusions by alluding to previous scandals in sport.

At the same time, I introduced a way for some competitors to inflate their own scores in a more 'legitimate' way. I picked a member of each team (usually those who had been particularly engaged with the game) and approached them on behalf of fictional sponsors ('Insurance', 'Fizzy Drinks', 'Crisps'), offering them the chance to earn bonus points as long as they competed wearing a hat emblazoned (in permanent marker) with the logo of that sponsor. I announced these sponsorship deals to the rest of the conference, overemphasising the notion that these people had 'earned' the ability to get more points by having the most points in the first place. Again, in putting this imbalanced structure in place, I was hoping to produce something of a negative reaction in players.

On the evening of the second day, the individual competition effectively closed, and I emphasised to players that they would need to register their medals in order to win. This meant that there was a huge rush of medal registrations at the end of the day, and delegates formed queues around the referees' desk. Even this added to the sense that the game was becoming less fun.

The goal of 'bureaucracy' was to frustrate players. My hope was that they would resort to cheating or gamebreaking in order to compete with a system that produced artificially inflated scores, and that this in turn would change the game. 


\section{Anarchy}

Day three, in my initial plan, was labelled 'anarchy'. With the individual competition over, I planned to disrupt the game further by making increasingly erratic and illogical decisions as the referee. Suddenly, bronze medals would be worth five times as many points, or I would decide that we had too many gold medals and start deducting points for each one that players handed in. The idea behind this was that I wanted to lay bare some of the arbitrary value that we attach to points and prizes in play and education settings, especially when those settings have been 'gamified'. In the end, I multiplied all of the team scores by a million in order to make the competition look more impressive. Of course, this still meant that the same team won, so it was a futile act of inflation.

The game ended after the final keynote, with the Blue team taking victory. I had made an underwhelming team prize (a large piece of cardboard cut into the conference logo and spray-painted gold) that had the potential to deflate all of the competitive spirit that players had built over the past few days. The Blue team stormed the stage to receive their prize, seemingly genuinely excited that they had won. This was a final piece of evidence that my plan had not necessarily come across in reality.

\section{Reality}

Though the game largely ran in line with this plan, two things occurred that surprised me.

- Firstly, delegates took the competition far more seriously than I thought they would. Given that this was a playful conference, I had assumed that delegates would, at best, 'play at' being competitive with each other. In practice, the top five spots on the medal table constantly shifted between delegates who genuinely engaged with the competition and who seemed to want to win.

- Secondly, and perhaps because of the first point, people were less bothered with the overarching plotline that I had developed. By the time the third day came around, people barely noticed the scores changing, and subsequently did not develop the frustration I was anticipating. Even for those who were engrossed in the competition, the bureaucracy became part of the fun. Indeed, it seemed as if my satirical bureaucracy became an actual one in which I was the chief bureaucrat. I missed quite a lot of the actual conference because I was too busy awarding and registering medals, or fixing problems with the tracking spreadsheet.

Something happened when the gameplan was put into action that simultaneously undermined my critical ideas about competition in play whilst highlighting its potential. In the following section, I will explore these surprises in more detail in order to link them back to ideas from the literature. 


\section{Discussion}

Looking back at the story of putting the plan into action, it is clear that things did not go exactly the way I planned, and I reflected on this after the conference, both as a designer and as a play scholar with an interest in competition. In doing so, I was keen to move beyond my own reflective thoughts and consider ideas from the game's players, so I put out a call on Twitter in the weeks following the conference and followed up via email with four delegates who expressed an interest in sharing their thoughts with me. I asked these volunteers to write specifically about their experiences of the game, and of competition within the game, but left questions fairly open to encourage discussion. Drawing these thoughts together with my own reflections, I have identified two ways in which the game demonstrated specific aspects of the relationship between play and competition. These aspects built upon, complicated, and even contradicted ideas that had emerged from literature.

\section{Competition encouraged cooperation}

It is unsurprising that a team-based competition would encourage cooperation between teammates; this is the definition of teamwork. Indeed, this idea fits with Moseley's (2012) notion that team competition can incorporate players that prefer competition and those who are averse to it. One participant said:

Being in a team gives you a sense of purpose and belonging and instant bonding with a group of people. It was an excuse to strike up conversation or to give encouragement and support to team members. Also, if you are competitive but not keen on self-promotion, being in a team gives you license to be more competitive and engaged because you are doing it 'for the team' and not for yourself. (Conference delegate, Purple team)

Beyond this, though, there was a sense that even the individual competition encouraged cooperation between members of different teams; the 'making friends' that I sought after. The two players who most consistently dominated the leader boards (one of whom eventually won) did so by challenging each other to dozens of ad hoc competitions, ensuring that both of them would receive at least a bronze medal each time. There seemed to be an acknowledgement between these players that they were playing the same game, and that in order to succeed they needed to cooperate in order to compete in the most efficient way. This could be read as a form of De Koven-esque 'coliberation'; equally, it might just be a shrewd, economic game-theory informed approach to the game. Either way, these two opposing competitors became friends in the same way that many teammates did across the conference.

This sense that competition encouraged cooperation was likely enabled by the specific form that the competition took. I used traditional signifiers of competition borrowed from sport in order to set the scene, and to provide an excuse for players to roleplay: 
I also loved the concept having an official, but playful start and finish, there being an element of roleplay / suspension of disbelief in the fact that there had been other iterations of the event before, a governing body making decisions behind the scenes, sponsorship opportunities etc. (Conference delegate, Yellow team)

This approach seemed to work to some extent, and links to Caillois' (1961, p. 73) idea that competition is contingent on mimicry through the rituals that surround sport and other competitions. One delegate summarised this, writing that it gave 'permission for silliness'. This did not necessary lead to bonding though; teams used their chants inconsistently, and it tended to be individuals rather than teams who most consistently 'performed' the Olympic-like rituals.

However, another accidental aspect did seem to lead to bonding, in that the most popular forms of competition were those that most strongly resembled childhood games. On the first evening, delegates seemed driven by nostalgia and quickly raided the box of primary school sports equipment in order to create impromptu obstacle races outside. These races had specific rules developed by delegates, and part of the process of taking part was being taken through the 'rules' by those who had invented the particular race in question. Observing this as a co-opted race official, I could not help but see this as reminiscent of children making friends by teaching each other the rules of invented games.

This is interesting because the literature seems to draw strong lines between child's play and play in adulthood, with competition being more of a feature of the latter than the former. Seeing adults connect and play by reverting to more 'childish' forms of play that include competition was surprising. This was enabled by the presence of playful 'tools', like the beanbags and cones, that were reminiscent of competition in childhood. It was a worthwhile reminder that competition can coexist with the more cooperative, imaginative play that scholars tend to emphasise in childhood.

All of this implies that competition and cooperation cannot be extricated from each other. At some level, everyone involved in the game is cooperating even when they compete, because keeping the game going requires cooperation. This, at the very least, suggests that the relationship between competition and cooperation is not as antagonistic as the divisions portrayed in the literature.

\section{Competition encouraged players to break the game}

Indeed, this cooperation-in-competition highlights another key feature of competition that I had not anticipated, in that competition encouraged players to break the game in unexpected ways.

In my plans, I had anticipated that players might react to an increasingly oppressive bureaucracy by explicitly breaking the rules. I had visions of the scoreboard being sabotaged, or players stealing medals from players 
who seemed to have been given an unfair advantage. This occurred to a small extent; at the end of the conference there were four one-penny pieces in the medal table, boosting their team's total ever so slightly, but not enough to change the score in any significant way.

This sense of deliberate frustration seemed to be limited because the game itself was more frustrating than I had planned, which left less space for subversion on my terms. Some players felt disconnected from the system of collecting points in the first place:

The point system was a little arbitrary. It depended on session leaders giving out points and not all session leaders bought into the token method... How the winners of the individual prize got their points was not totally transparent which again was disincentive. (Conference delegate, Yellow team)

There is a sense, though, that players broke the rules for different reasons and in different ways that went beyond simply 'cheating'. Rather than cheating in order to succeed in the game as it was presented, players negotiated with the rules and each other in order to take what they wanted from the game. The most obvious example of this is the case of the two leading competitors outlined above; they negotiated with each other in order to win the game. Other delegates set their own limits around their actions, contributing within the limits of their own sense of competitiveness, but no further. One delegate might roll up their sleeves and win a huge number of medals from all sections of the conference; for another, it might be enough to wear a colourful tie and take part in a quiz during one of the sessions. A delegate from the Blue team appreciated that 'everyone could engage to the extent they were comfortable with', and a Yellow team member said that 'being part of the team, but being able to be as competitive as you liked within that sphere was the perfect balance for me'.

What players were doing here was effectively redefining 'success' without me forcing them to. 'Success' meant different things for those who were trying to top the medals table, and those who just wanted to engage with new people at a new conference. This relates to events on the final day; I found that players did not care as much as I did about the way in which the scores kept changing, precisely because they had already dismissed the point system as arbitrary. I felt less able to play with the scoring system in order to point out how arbitrary the value of 'winning' is because, for some delegates, winning in terms of points was no longer the point of the game. They had already redefined success so I did not have to. The Blue team storming the stage to claim their prize felt less about the points they had won, and more about the way in which they had bonded as a team.

This hints at another connection to Caillois, but this time one that challenges his conception. For him, competition and 'vertigo' (i.e. chaotic play) are incompatible as the latter undermines the former by diluting the tension and regulations that surround competition (1961, p. 72). It might seem that a less 'tense' competition is less competitive, but I found that 'diluting' competition in this context meant spreading it out to others, even if this meant that it did not mean what I had intended it to mean. Instead of destroying competition, then, player- 
directed chaos created different forms of tension that could become new sites for competitive behaviour.

\section{Limitations}

This is, of course, a limited argument based on just a single experimental design (despite some confusion over whether I had actually run the Conference Games 22 times prior to this event). It is limited in turn by the informal way in which I gathered feedback from a small number of delegates. However, I have tried to temper their views with my own reflections on the game as a whole.

This case study is also limited in its applicability because of the nature of the conference. Playful Learning is exactly the sort of space where participants might be up for this sort of activity, even if they are relative newcomers to it. There was an extent to which I designed something for this specific audience, and that a competitive, playful activity like this might not work in the same way in less playful settings (Whitton \& Moseley, 2019, p. 179).

Despite these limitations, there is something to build on. Whilst I have not proven anything fundamental about the nature of competition through experimenting with this game, it has allowed me to explore and highlight aspects that can often be ignored. I am still convinced of the power of games to make people think and to deliver messages about both play and the world, but designers and researchers need to consider the ways in which their games will be played, and the ways in which their messages might change upon transmission.

\section{Concluding thoughts}

I set out to reach three goals with this game, so it is useful to return to these as I conclude:

- Firstly, I wanted to design a game that would provide a playful space for conference delegates to interact with each other, and my observations and informal feedback seem to suggest that the game did this. However, it did not necessarily do this for the reasons I intended.

- Secondly, I wanted to run an 'experiment' in competition that would explore some of the perceived tensions between play and competition. Based on my discussion above, I would argue that these have been explored, to the extent that they might not even be tensions.

- Thirdly, I had the personal goal of pushing myself out of my comfort zone as an educator and designer by engaging with concepts that I would normally avoid. Again, I did this, but in the process (re)discovered a vein of play that was far more closely tied to my own play preferences than I had anticipated.

For all three of these goals, I have found that competition has a far more complicated relationship with play than might be suggested by both theoretical and practical perceptions. Competition is clearly not the only thing 
that play has to offer, but similarly we cannot dismiss competition out of hand in playful settings. It can provide structure and an incentive to get involved for participants, but (like many other aspects of play) can also provide the means to undermine and co-opt this structure. In this way, this small-scale experiment contributes to a wider discussion of competition in play by highlighting the potential of competition. My own goal is to build competition into educational activities where I might not have before, and I hope that this inspires others to include subversive competition in their own playful activities.

\section{Acknowledgements}

Thanks to the Playful Learning conference committee for the opportunity to run the conference game, the delegates who took part in both the game and the post-conference discussion, and especially to the team of 'referees' who helped manage the bureaucracy.

\section{References}

Bartle, R. A. (1996). Hearts, clubs, diamonds, spades: Players who suit MUDs. Retrieved from https://mud.co.uk/richard/hcds.htm

Bateman, C. (2018). Playing work, or gamification as stultification. Information, Communication E Society, 21(9), 1193-1203. https://doi.org/10.1080/1369118X.2018.1450435

Brown, S. (2009). Play: How it shapes the brain, opens the imagination, and invigorates the soul. New York, NY: Avery.

Brown, W. (2015). Undoing the demos: Neoliberalism's stealth revolution. New York, NY: Zone Books.

Caillois, R. (1961). Man, play and games. Urbana: University of Illinois Press.

Comedy Central (2014) Kroll Show - Making friends [Video file]. Retrieved from https://www.youtube.com/watch?v=oc85rAyNhzY

Connell, R. (2019). The good university: What universities actually do and why it's time for radical change. London: Zed Books.

Davies, W. (2014). The limits of neoliberalism: Authority, sovereignty and the logic of competition. London: SAGE. de Albuquerque, R. M., \& Fialho, F. A. P. (2015). Fun and games: Player profiles. The Computer Games Journal, 4(1), 31-46. https://doi.org/10.1007/s40869-015-0003-y

De Koven, B. (2013). The well-played game: a playful path to wholeness (3rd ed.). Cambridge, MA: MIT Press. Flanagan, M. (2009). Critical play: radical game design. Cambridge, MA: MIT Press. 
Huizinga, J. (1949). Homo ludens: a study of the play element in culture. Kettering: Angelico Press.

Hutt, C. (1981). Toward a taxonomy and conceptual model of play. In H. I. Day (Ed.), Advances in intrinsic motivation and aesthetics (pp. 251-298). Boston, MA: Springer.

Juul, J. (2005). Half-real: video games between real rules and fictional worlds. Cambridge, MA: MIT Press.

Kohn, A. (1992). No contest: the case against competition (Rev. ed.). Boston, MA: Houghton Mifflin.

Kolb, A., Y., \& Kolb, D., A. (2010). Learning to play, playing to learn: A case study of a ludic learning space. Journal of Organizational Change Management, 23(1), 26-50. https://doi.org/10.1108/09534811011017199

Moseley, A. (2012). Competition: Playing to win? In N. Whitton \& A. Moseley (Eds.), Using games to enhance learning and teaching: A beginner's guide (pp. 57-66). Abingdon: Routledge.

Piatt, K. (2019). Designing conference games. In N. Whitton \& A. Moseley (Eds.), Playful learning: Events and activities to engage adults (pp. 124-134). Abingdon: Routledge.

Playful Learning Conference (2019). Playful learning. Retrieved from http://conference.playthinklearn.net/blog/

Salen, K., \& Zimmerman, E. (2003). Rules of play: game design fundamentals. Cambridge, MA: MIT Press.

Sicart, M. (2014). Play matters. Cambridge, MA: MIT Press.

Suits, B. (1978). The grasshopper: Games, life, and utopia (3rd ed.). Ontario: Broadview Press.

Sutton-Smith, B. (1997). The ambiguity of play. Cambridge, MA: Harvard University Press.

Whitton, N. \& Moseley, A. (2019). Future play. In N. Whitton \& A. Moseley (Eds.), Playful learning: Events and activities to engage adults (pp. 177-180). Abingdon: Routledge.

Lean, J. (2019). Total play! Exploring participation and play in higher education. (Doctoral thesis). Retrieved from http://e-space.mmu.ac.uk/623905/ 